\title{
The differential effects of reinforcement and testosterone on aggressive responding in pigeons: Species typical and aversive aspects of pigeon aggression*
}

\author{
AUGUSTUS R. LUMIA \\ Skidmore College, Saratoga Springs, N.Y. 12866 \\ CORINNE A. RIEDER \\ North Dakota State University, Fargo, N. Dak. 58102 \\ and \\ JAMES H. REYNIERSE \\ Hope College, Holland, Mich. 49423
}

Pigeons lowest in their dominance hierarchies were either injected with testosterone, conditioned to attack more dominant birds, or both within an operant chamber. Birds injected with testosterone alone failed to exhibit any increase in aggressive responses against opponents. Those reinforced for attacking opponents showed a marked increase in aggressive behavior. However, the greatest enhancement of attack behavior was found in those birds given a combination of testosterone and conditioning. In addition, there were substantial topographical differences in the fighting behaviors exhibited by the birds exposed to the various treatments. Birds administered a combination of testosterone and conditioning or conditioning alone elicited extreme escape-like behaviors in their opponents. These behaviors were not produced in the opponents of birds injected with testosterone alone or saline. These results are discussed in terms of an interaction between the androgen and learned responses.

Both learning and hormonal factors are recognized as important determinants of aggression. Androgens have been found to increase the incidence of aggressive behavior in a number of species (Beach, 1948; Manning, 1967), and aggression can be both acquired and maintained through positive reinforcement in pigeons (Skinner, 1959; Reynolds, Catania \& Skinner, 1963; Lumia, 1967; Willis \& Lumia, 1968) and rats (Ulrich, Johnston, Richardson, \& Wolff, 1963).

Little information exists, however, on the relative effects of hormones and learning and their possible interactive effect. The present study examined the effects of positive reinforcement, injections of testosterone, or both on the aggressive behavior of individual male pigeons. While the primary conditioning effects are reported elsewhere (Lumia, 1972), we now report that striking qualitative behavioral differences accompanied

*Support for the preparation of this manuscript was provided by the Faculty Research Committee, Skidmore College, and a grant from Merck Sharp and Dohme Pharmaceutical Company to the senior author. Reprints may be obtained from Augustus R. Lumia, Department of Psychology, Skidmore College, Saratoga Springs, New York 12866. conditioning and have important implications for analyses of aggression.

Eighty sexually mature yearling male White Carneaux pigeons were assigned randomly to 16 groups of five each, and a mature hen was placed in each loft to maintain a high level of dominance interaction. The 16 male birds lowest in the dominance hierarchies of their respective lofts were the critical Ss and were assigned to four groups of four Ss each. An additional male pigeon not belonging to any group was the initial target for all critical Ss.

\section{METHOD}

Apparatus

During initial observations, the birds were housed in wood and chicken-wire home lofts, $183 \times 183 \times 183 \mathrm{~cm}$. During conditioning, birds were housed in individual plywood and hardware cloth cages, $25 \times 44 \times 28 \mathrm{~cm}$. The conditioning chamber, constructed of hardware cloth and plywood, was $61 \times 61 \times 46 \mathrm{~cm}$ wide. Centered at one end of this chamber was a $5-\mathrm{cm}$ circular opening with a guillotine door through which mixed grain reinforcement could be presented. Directly above this door was a 4-cm red disk. A Lafayette hand counter was used to count pecks during treatment.

\section{Procedure}

Each of the 16 groups was housed together for $48 \mathrm{~h}$ prior to initial observations. To determine the dominance hierarchy, the pigeons were then observed during the 12-h lights-on period for two $30-\mathrm{min}$ periods on each of 3 consecutive days. The least-dominant cock in each group was removed from the home loft, placed in an individual cage, and deprived of food until its weight stabilized at $75 \%$ of its free-feeding weight. The remaining four male birds from each loft were also individually housed but were not food deprived.

Each S was assigned randomly to one of four experimental treatment groups and was placed in the conditioning chamber for adaptation periods of $1 \mathrm{~h}$ each day for 2 days prior to the beginning of treatment.

In the conditioning group (Group $\mathrm{C}$ ), each pigeon was first shaped to peck the red disk for grain reinforcement. After 50 reinforcements on a continuous reinforcement (CRF) schedule, the $S$ was shaped to peck the unrestrained target bird. For the next 2 days, the $S$ was given two 20-min sessions per day with reinforcement on a variable ratio (VR) 11 schedule for pecking the target bird. Thereafter, the $S$ met each of the birds from his home loft for four 20-min sessions and pecking was reinforced on a VR 11 schedule. The number of pecks delivered by the $S$ was recorded for each session. The order in which opponents were presented was randomized, but the four sessions with a particular opponent were consecutive, consisting of two sessions per day on each of 2 successive days. The two daily sessions were always separated by at least a $7-\mathrm{h}$ interval.

In the group treated with testosterone (aqueous solution, $25 \mathrm{mg} / \mathrm{cc}$ Lilly, Group H), each S was paired first with the target bird, then with each of its home loft opponents, as described for Group C, but pecking was not reinforced. Testosterone $(10 \mathrm{mg} / \mathrm{kg}$ body weight) was injected into the pectoral muscle 


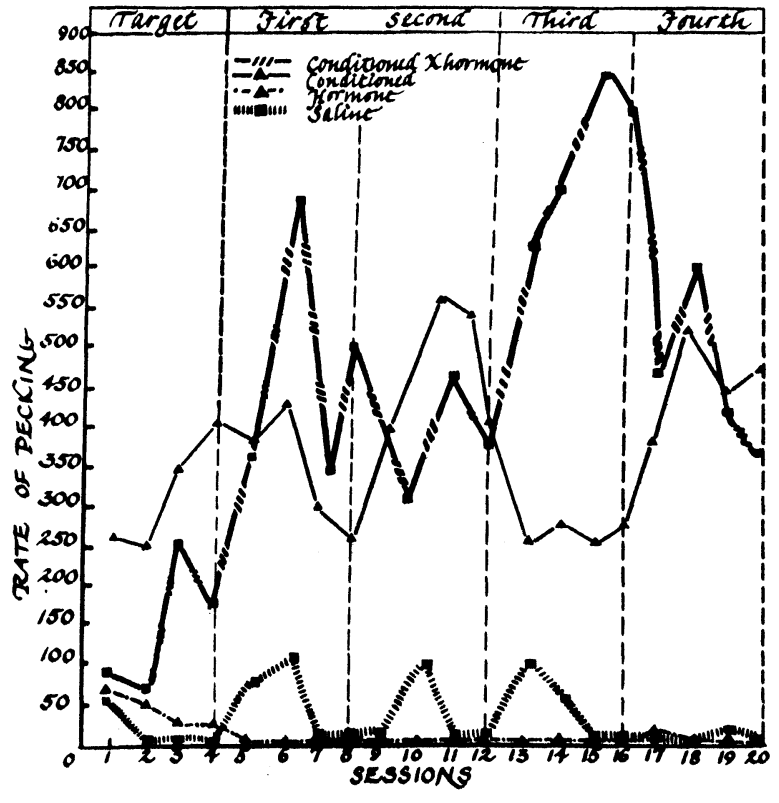

Fig. 1. Rate of pecking target and home loft opponents over 20 experimental sessions for a typical intermediate $S$ from each of the four experimental groups.

every other day for 10 days. The first injection was given 1 day before the initial encounter with the target bird, and subsequent injections were administered at least $2 \mathrm{~h}$ before an experimental session.

Ss which received both conditioning and hormones (Group $\mathrm{C}+\mathrm{H}$ ) were trained to peck first the disk, then the target bird and were then paired with the target bird and home loft opponents as in Group C. They received testosterone on the same schedule as the Ss in Group $\mathrm{H}$. The first injection was given the day before a S's initial encounter with the target bird and after it had acquired the disk-pecking response.

Ss in the saline control group (Group S) received the same treatment as Group H, except that the injection was physiological saline instead of hormone. Pecking was not reinforced.

\section{RESULTS AND DISCUSSION}

The number of pecks per session for an intermediate $S$ from each condition is presented in Fig. 1. In general, individual birds in Groups $\mathrm{C}+\mathrm{H}$ and $\mathrm{C}$ showed the highest rates of pecking, while rate of pecking in Groups $\mathrm{S}$ and $\mathrm{H}$ were very low, often falling to zero. An analysis of variance indicated that treatment was significant as a main effect $(F=20.686, d f=3 / 9)$. The interaction between sessions and treatment also was significant $(\mathrm{F}=4.504, \mathrm{df}=9 / 27)$, reflecting the significantly higher increase in pecking rate for $\mathrm{C}+\mathrm{H}$ conditions over sessions than for $\mathrm{C}$ conditions. A complete account of the pecking data is presented in Lumia (1972).

Though peck rates for opponent birds were not recorded, some general patterns of behavior emerged. During the initial encounter with a $\mathrm{C}$ or $\mathrm{C}+\mathrm{H}$ bird, the opponent typically pecked and fought vigorously for a short time. Then, as attacks continued, he became extremely passive and finally showed frantic escape behaviors, jumping, flapping his wings, and hitting his head against the cover of the chamber. In subsequent sessions the opponent fought back less, sometimes not at all, and alternated between passivity and escape. The opponents of $\mathrm{H}$ and $\mathrm{S}$ birds behaved quite differently, showing no escape attempts and alternating between short attacks and increasingly longer periods of no contact. The Ss in Groups $\mathrm{H}$ and $\mathrm{S}$ showed little or no escape behavior under these short attacks.

There was a striking qualitative difference in response topography between every bird that received conditioning only and every bird that received both conditioning and testosterone. The pecking of Group $\mathrm{C}$ birds was not accompanied by the usual strutting, cooing, and wing flapping which typify normal fighting in pigeons. These components were often present during the initial session with a new opponent but quickly dropped out, probably because reinforcement was contingent only on pecking. The pecking seemed mechanical and was often interrupted by trips to the food hopper. In marked contrast, the birds in Group $\mathrm{C}+\mathrm{H}$ engaged in full-blown aggressive behavior which did not drop out. Furthermore, $\mathrm{C}+\mathrm{H}$ birds often continued to fight after reinforcement was made available. It may well be that the pecking by $\mathrm{C}$ birds was primarily directed toward food reinforcement and was not truly aggressive in nature. The addition of hormone treatment, then, to behavioral manipulation may produce a pigeon which is, in fact, truly more aggressive, even though the hormone treatment alone did not increase pecking.

Such qualitatively dissimilar results suggest that attempts to study or modify aggressive or dominance behavior must clearly distinguish between a single operant, such as pecking, and the complex combinations of internal and external responses which characterize naturally occurring aggressive interaction. It cannot be assumed that reinforcing a single response has increased aggression in an animal, even if the animal shows increases in that particular response or subsequently rises in a dominance hierarchy.

\section{REFERENCES}

Beach, F. A. Hormones and behavior. New York: Hoeber, 1948 Lumia, A. R. The relationship of conditioned pecking to position in the dominance hierarchy in pigeons. Master's Thesis, University of Missouri at Kansas City, 1967.

Lumia, A. R. The relationships among testosterone, conditioned aggression, and dominance in male pigeons. Hormones \& Behavior, 1972, 3, 277-286.

Manning. A. An introduction to animal behavior. Reading, Mass: Addison-Wesley, 1967.

Reynolds, G. S., Catania, A. C., \& Skinner, B. F. Conditioned and unconditioned aggression in pigeons. Journal of the Experimental Analysis of Behavior, 1963, 6, 73-74.

Skinner, B. F. An experimental analysis of certain emotions Journal of the Experimental Analysis of Behavior, 1959, 2, 264 (abstract).

Ulrich, R. E., Johnston, M., Richardson, J., \& Wolff, P. C. The operant conditioning of fighting behavior in rats. Psychological Reports, 1963, 13, 465.

Willis, F. N., \& Lumia, A. R. Conditioned fighting and dominance in pigeons. Psychonomic Science, 1968, 10, 187-188.

(Received for publication December $11,1972$. 